$09 ; 15$

\title{
Усилитель яркости на переходах атома марганца с частотой следования импульсов до $100 \mathrm{kHz}$
}

\author{
(C) М.В. Тригуб ${ }^{1,2}$, Д.В. Шиянов ${ }^{1}$, В.Б. Суханов ${ }^{1}$, Т.Д. Петухов ${ }^{1,2}$, \\ Г.С. Евтушенко ${ }^{1,2}$ \\ ${ }^{1}$ Институт оптики атмосферы им. В.Е. Зуева СО РАН, Томск, Россия \\ ${ }^{2}$ Томский политехнический университет, Томск, Россия \\ E-mail: trigub@tpu.ru \\ Поступило в Редакцию 10 сентября 2018 г.
}

\begin{abstract}
Представлены результаты разработки и исследования усилителя яркости изображений на переходах атома марганца для задач визуализации объектов в активных оптических системах. Показана принципиальная возможность использования разработанного активного элемента для визуализации объектов и процессов в двух спектральных диапазонах: видимом и ближнем ИК. Получены профили пучка излучения активного элемента при частоте следования импульсов до $100 \mathrm{kHz}$.
\end{abstract}

DOI: $10.21883 /$ PJTF.2018.24.47041.17523

В последние годы интерес к активным средам на парах металлов обусловлен возможностью создания скоростных усилителей яркости (УЯ) видимого и ближнего ИК-диапазонов спектра. Они используются для построения активных оптических систем (АОC) для визуализации объектов и быстропротекающих процессов в условиях мощной фоновой засветки - лазерных мониторов (ЛМ). Традиционный метод лазерной подсветки [1] при больших уровнях засветки может оказаться непригодным. В этом случае эффективно работают ЛМ с УЯ на переходах атома меди [2]. Расширение спектрального диапазона АОС предполагает разработку эффективных УЯ на переходах различных металлов. Такие исследования были проведены для различных сред, например железа [3], однако получить достаточный уровень сверхизлучения не удалось. Одной из перспективных сред для построения АОС, на наш взгляд, является среда на парах марганца, в которой усиление одновременно реализуется на переходах в видимой и ближней ИК-областях спект- 
pa [4]. Это позволит производить визуализацию в данных спектральных диапазонах, а также преобразовывать изображения из ИК- в видимый диапазон. Метод преобразования основан на взаимодействии излучения в среде на двух связанных переходах атома марганца. Насыщение усиления на одном из связанных переходов приводит к значительной амплитудной модуляции усиления (излучения) на другом [5]. В отличие от меди природный марганец имеет один изотоп $\mathrm{Mn}^{55}$, соответственно ширины компонент сверхтонкой структуры составляют менее 1 pm [6]. Это обеспечит узкополосное усиление сигнала, несущего информацию об объекте, при этом достигается глубокая фильтрация сигнала от излучения широкополосной засветки. Как известно, временно́е разрешение АОС ограничивается частотой следования импульсов (ЧСИ) УЯ, и лучшее значение $\left(10^{-5} \mathrm{~s}\right)$ получено для активной среды на парах меди при частоте следования импульсов $100 \mathrm{kHz}$ [2].

В настоящей работе представлены результаты исследования характеристик излучения и усиления активной среды $\mathrm{MnCl}_{2}$ в широком диапазоне ЧСИ накачки (от 10 до $100 \mathrm{kHz}$ ). Определен вклад линий видимого и ИК-диапазонов спектра в суммарную мощность излучения. Измерены радиальные профили излучения, определяющие поле зрения и качество получаемого изображения, проведена визуализация тестобъекта.

Использовался активный элемент на парах хлорида марганца с длиной активной зоны $30 \mathrm{~cm}$ и диаметром $1 \mathrm{~cm}$, давление буферного газа $(\mathrm{Ne})$ составляло 30 Torr. Возбуждение активной среды производилось по схеме прямого разряда накопительного конденсатора через импульсный трансформатор [7]. Измерение электрических характеристик разряда осуществлялось с помощью датчика тока Pearson Current Monitor 8450, датчика напряжения Tektronics P6015A и осциллографа LeCroy WJ-324. Коммутатором на низких частотах следования служил тиратрон ТГИ1-1000/25, на высоких - таситрон ТГУ1-1000/25. Для регистрации импульсов излучения применялись фотодиоды Thorlabs DET 10N/M (для ИК-диапазона) и DET 10A/M (для видимого диапазона).

Для диапазона частота от 10 до $20 \mathrm{kHz}$ максимальная мощность генерации получена на ЧСИ $17 \mathrm{kHz}$. При этом емкость накопительного конденсатора составляла $500 \mathrm{pF}$, напряжение на выпрямителе устанавливалось $4.4 \mathrm{kV}$, ток $150 \mathrm{~mA}$. Средняя мощность по всем линиям излучения составила $500 \mathrm{~mW}$. Спектральные исследования показали, что в видимой области спектра излучения присутствуют линии $534.1 \mathrm{~nm}$

Письма в ЖТФ, 2018, том 44, вып. 24 

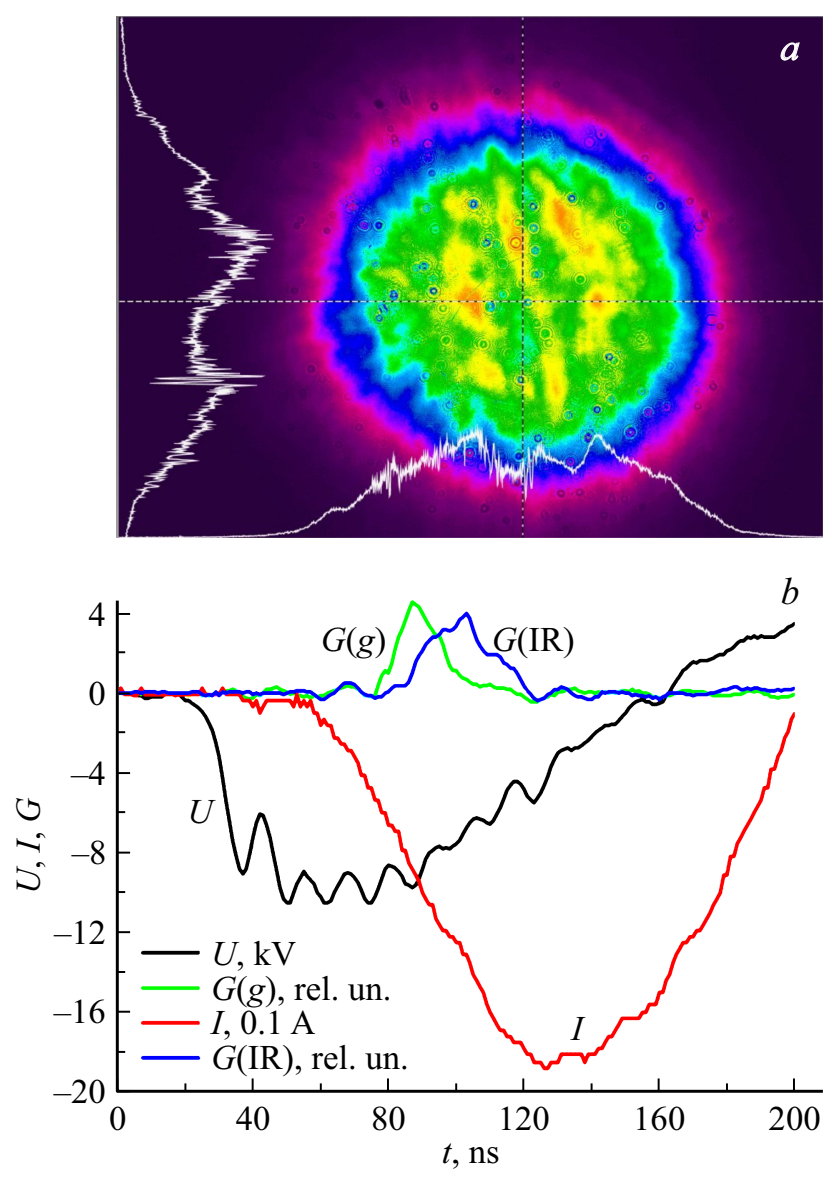

Рис. 1. $a-$ профиль генерации, $b-$ осциллограммы импульсов напряжения на ГРТ $(U)$, тока через ГРТ $(I)$, излучения на переходах видимого диапазона $(G(g))$ и ИК-диапазона $(G(\mathrm{IR}))$.

и $542.0 \mathrm{~nm}$, при этом бо́льшая часть излучения сосредоточена на линии $534.1 \mathrm{~nm}$. В ИК-области спектра зафиксированы линии 1290, 1330 и $1360 \mathrm{~nm}$, имеющие общие нижние рабочие уровни с линиями видимого диапазона спектра. Следовательно, при визуализации объекта

Письма в ЖТФ, 2018, том 44, вып. 24 
на основных ИК-линиях 1290 и $1330 \mathrm{~nm}$ возможно формирование негативного изображения в зеленом цвете.

Импульсы напряжения на газоразрядной трубке (ГРТ), тока через ГРТ и излучения показаны на рис. $1, b$. Длительности импульсов излучения составляют $10-15 \mathrm{~ns}$ для линий видимого диапазона, $15-20 \mathrm{~ns}$ для ИК-линий. Профиль пучка генерации представлен на рис. $1, a$. Можно отметить, что он достаточно однороден.

Результаты визуализации тестового объекта (щель монохроматора с максимальным раскрытием $4 \mathrm{~mm}$ ) в схеме ЛМ [8] представлены на pис. 2. На рис. $2, a$ показано изображение, полученное в зеленом спектре усиления, на рис. $2, b-$ изображение в ИК-спектре усиления.

Можно отметить, что с точки зрения получения максимального контраста формируемого изображения существует оптимум, который отличается от условий, обеспечивающих максимальную мощность генерации. Наибольшая область зрения и контраст получаемого изображения достигаются при меньшей концентрации паров рабочего вещества. Аналогичные результаты были получены ранее для активной среды на переходах атома меди $[2,8]$. При повышении мощности накачки с 341 до $422 \mathrm{~W}$ происходило увеличение контраста. Дальнейшее повышение мощности накачки приводит к уменьшению области зрения АОС из-за уменьшения диаметра усиления среды. Низкий контраст изображений, формируемых на ИК-переходах УЯ, на наш взгляд, объясняется используемой регистрирующей аппаратурой. Использовался электроннооптический преобразователь, с помощью которого формировалось изображение на экране. Для регистрации таких изображений целесообразно использовать SWIR-камеры.

Далее было проведено исследование возможности работы данного активного элемента при повышенных ЧСИ (до $100 \mathrm{kHz}$ ). Для этого схема накачки была модифицирована, в качестве коммутатора был использован таситрон ТГУ1-1000/25. На рис. 3 представлены осциллограммы импульсов напряжения на ГРТ, тока через ГРТ, импульса генерации при ЧСИ $100 \mathrm{kHz}$, а также профиль пучка генерации при указанной ЧСИ. Средняя мощность излучения достигала $320 \mathrm{~mW}$, а соотношение мощностей составляло $270 \mathrm{~mW}$ (ИК-диапазон) и $84 \mathrm{~mW}$ (видимый диапазон). Повышение частоты следования импульсов приводит к перераспределению мощности генерации в сторону ИК-спектра. Этот факт накладывает определенные ограничения на возможность использования высокочастотных УЯ на переходах атома марганца

Письма в ЖТФ, 2018, том 44, вып. 24 

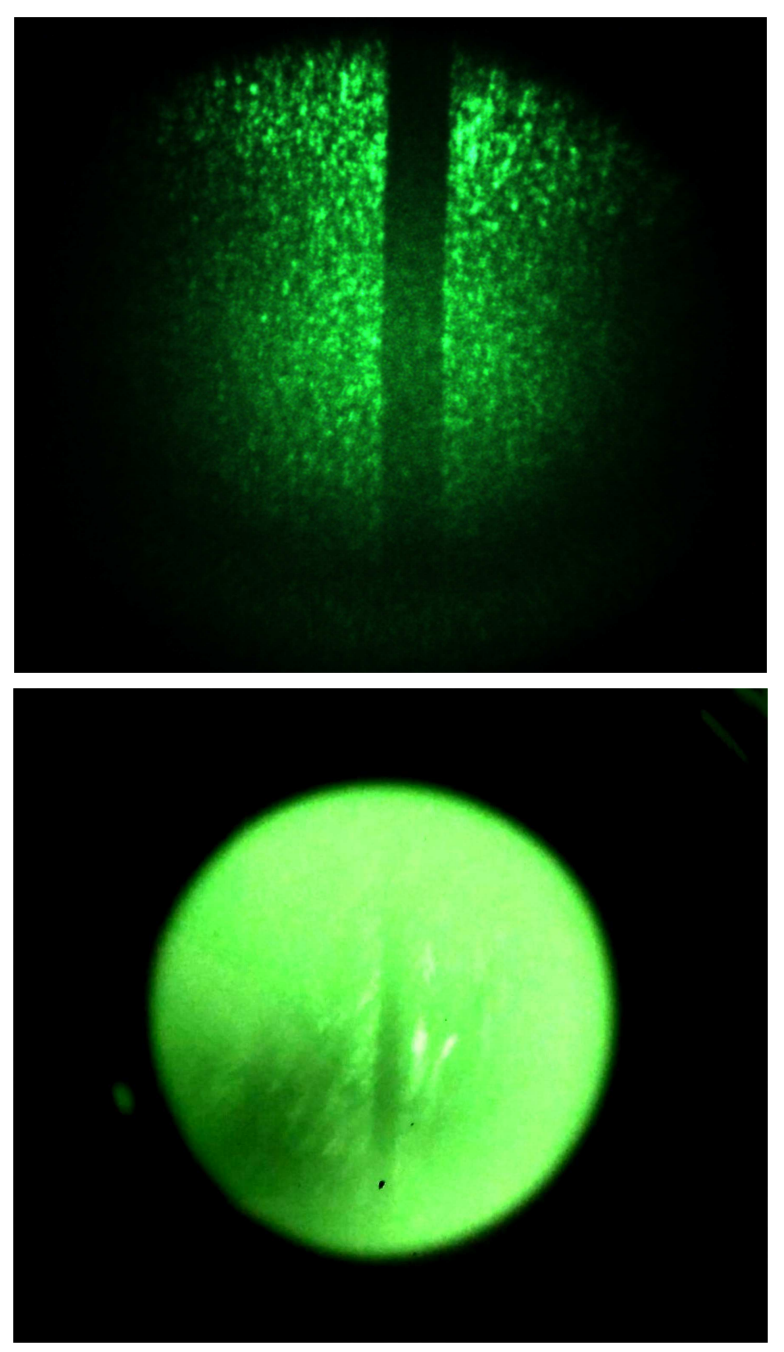

Рис. 2. Визуализации цели монохроматора в ЛМ при использовании усиления на переходах видимого диапазона $(a)$ и ИК-диапазона $(b)$.

Письма в ЖТФ, 2018, том 44, вып. 24 

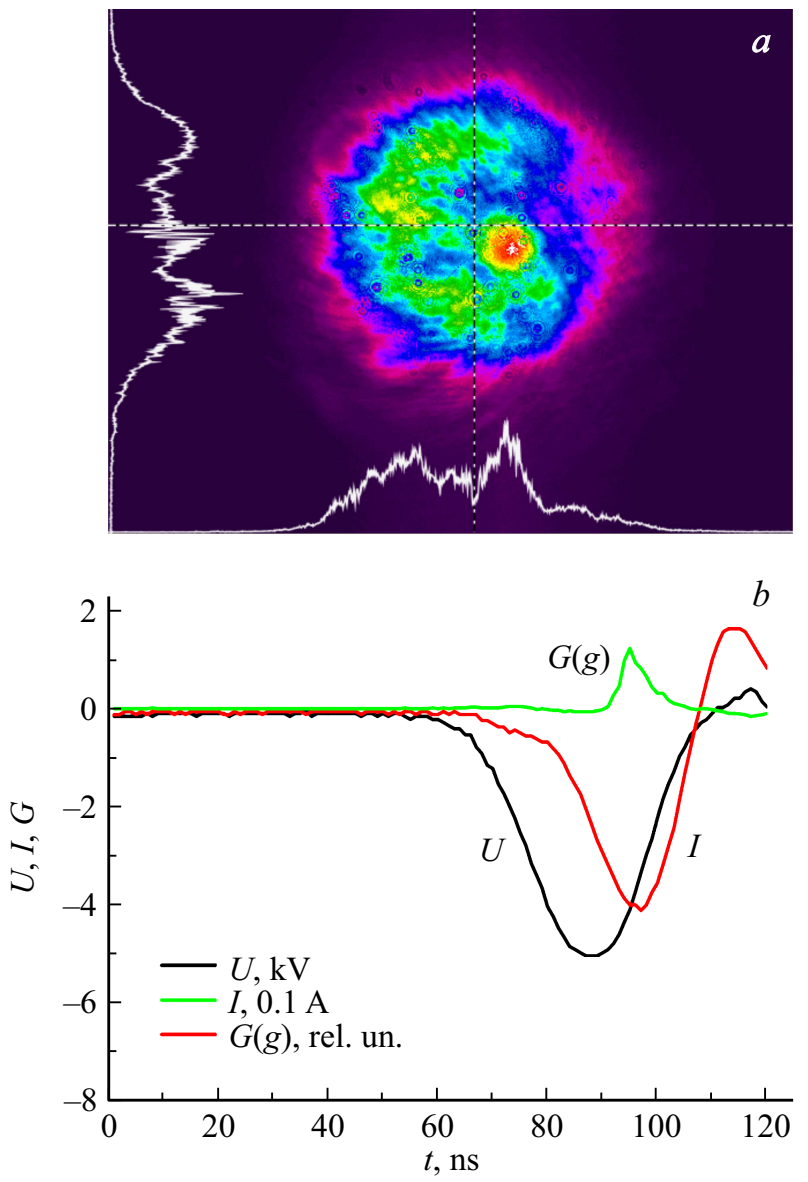

Рис. 3. $а-$ профиль генерации при ЧСИ $100 \mathrm{kHz}$ без добавки $\mathrm{HCl}$, $b$ - осциллограммы импульсов напряжения на ГРТ $(U)$, тока через ГРТ $(I)$, излучения $(G)$.

для визуально-оптической диагностики быстропротекающих процессов. Ограничение связано с доступной высокоскоростной регистрирующей аппаратурой. Наибольшее распространение имеют видеорегистраторы видимой области спектра.

Письма в ЖТФ, 2018, том 44, вып. 24 
Одним из способов улучшения частотно-энергетических и усилительных характеристик активных сред на парах металлов и их галогенидов является использование водородсодержащих добавок [9]. С учетом того, что в работе использовался хлорид марганца, в качестве добавки мы применили $\mathrm{HCl}$. При ЧСИ $17 \mathrm{kHz}$ добавка положительно повлияла на мощность и профиль излучения. Однако при ЧСИ $100 \mathrm{kHz}$ добавка $\mathrm{HCl}$ в активную среду приводила к уменышению мощности излучения и ухудшению однородности профиля пучка. Этот факт требует дополнительного исследования. Наиболее вероятно, что для получения положительного эффекта использования водородсодержащей добавки необходимо увеличивать энерговклад в активную среду.

Таким образом, в ходе работы был изготовлен активный элемент на переходах атома марганца и проведено исследование его частотноэнергетических и усилительных характеристик, в том числе при высоких частотах следования импульсов накачки (до $100 \mathrm{kHz})$. Исследованы спектральный состав и распределение мощности излучения в видимой и ближней ИК-области спектра, которые демонстрируют возможность преобразования ИК-изображений в видимый диапазон за счет конкуренции по рабочим переходам УЯ. Профиль излучения (усиления) позволяет получать изображения с минимальными искажениями. На основе разработанного УЯ была реализована АОС, проведены первые эксперименты по визуализации тестового объекта. Выполненные исследования позволяют сделать вывод о возможности использования данной среды в лазерных мониторах, построенных как по моностатической [8], так и по бистатической схеме [10].

Разработка скоростных усилителей яркости на переходах атомов металлов выполнена в рамках продолжения исследований по проекту Российского научного фонда № 14-19-00175, работа по созданию эффективных источников излучения видимого и ближнего ИК-диапазонов проведена в рамках ГЗ АААА А17-117021310150-0.

\section{Список литературы}

[1] Webb C.E., Jones J.D.C. Handbook of laser technology and applications. IOP Publishing, 2004. V. 3. 1180 p.

[2] Евтушенко Г.С., Казарян М.А., Торгаев С.Н., Тригуб М.В., Шиянов Д.В. Скоростные усилители яркости на индуцированных переходах в парах металлов. Томск: STT, 2016. 245 с.

Письма в ЖТФ, 2018, том 44, вып. 24 
[3] Суханов В.Б., Шиянов Д.В., Тригуб М.В., Димаки В.А., Евтушенко Г.С. // Письма в ЖТФ. 2016. Т. 42. В. 6. С. 84-89.

[4] Little C.E. Metal vapor lasers: physics, engineering \& applications. Chichester: Willey, 1998. $620 \mathrm{p}$.

[5] Земсков К.И., Казарян М.А., Петраш Г.Г. // Письма в ЖЭТФ. 1985. Т. 42. B. 6. C. $260-263$.

[6] Климовский И.И., Морозов А.В. // Квантовая электроника. 1986. Т. 13. В 4. C. $828-830$.

[7] Тригуб М.В., Власов В.В., Шиянов Д.В., Суханов В.Б., Троицкий В.О. // Оптика атмосферы и океана. 2017. Т. 30. В. 12. С. 1069-1072.

[8] Кузнецов А.П., Бужсинский Р.О., Губский К.Л., Савелов А.С., Саранцев С.А., Терехин А.Н. // Физика плазмы. 2010. Т. 36. В. 5. С. 463-472.

[9] Boichenko A.M., Evtushenko G.S., Torgaev S.N. // Phys. Wave Phenom. 2011. V. 19. N 3. P. 189-201.

[10] Тригуб М.В., Торгаев С.Н., Евтушенко Г.С., Троицкий В.О., Шиянов Д.В. // Письма в ЖТФ. 2016. Т. 42. В. 12. С. 51-56. 